\title{
Development of an Indirect ELISA Featuring Plates Coated with Column Chromatographically Purified Canine Adenovirus Type-1 Antigen
}

\author{
Dong-Kun Yang ${ }^{\star}$, Ha-Hyun Kim, Siu Lee, Miryeon Ji, Bok Hee Han, Soobin Oh, Bang-Hun Hyun
}

Viral Disease Research Division, Animal and Plant Quarantine Agency, MAFRA, Gimcheon, 39660, Republic of Korea

\author{
Corresponding \\ Dong-Kun Yang, Ph D, DVM \\ Animal and Plant Quarantine Agency, 177 \\ Hyeoksin 8-ro, Gimcheon-si, Gyeongsangbuk- \\ do 39660, Republic of Korea \\ Phone : +82-54-912-0785 \\ Fax : $+82-54-912-0812$ \\ E-mail : yangdk@korea.kr
}

Received : December 7, 2019

Revised : February 16, 2019

Accepted : February 18, 2020

No potential conflict of interest relevant to this article was reported.

\section{Copyright (c) 2020 Journal of Bacteriology} and Virology

(c) This is an Open Access article distributed under the terms of the Creative Commons Attribution Non-Commercial License (http://creativecommons.org/ license/by-nc/3.0/).
Canine adenovirus type 1 (CAV-1) causes infectious hepatitis in members of the family Canidae, including dogs. An indirect enzyme-linked immunosorbent assay (I-ELISA) that detects CAV-1 antibodies is required for large-throughput tests of dog sera. We collected 165 serum samples from dogs of Chungbuk and Gyeongbuk provinces between February 2016 and October 2018. The Korean CAV-1 vaccine strain CAV1V was propagated in Madin-Darby canine kidney (MDCK) cells and purified via Nuvia cPrime anion-exchange chromatography; the virus served as an I-ELISA antigen. Virus-neutralizing anti-CAV-1 titers in dog sera were measured using the virus neutralization (VN) method. The I-ELISA was optimized using purified CAV-1 antigen and serum samples. This kit was used to evaluate dog sera. The VN and I-ELISA data were compared. The sensitivity, specificity, and accuracy of the I-ELISA were $97.0 \%, 74.2 \%$, and $92.7 \%$ compared to the VN assay, respectively. The I-ELISA data significantly correlated with those of VN $(r=0.88)$. These results suggest that the I-ELISA is useful for serosurveillance of CAV-1 in dog sera.

Key Words: CAV-1, I-ELISA, sero-surveillance

\section{INTRODUCTION}

Canine adenoviruses (CAVs) of the genus Mastadenovirus in the family Adenoviridae have been classified into CAV types 1 and 2 via molecular genomic analyses and biological assays (hemagglutination [HA] and virus neutralization [VN] assays) (1, 2). The CAVs contain $35 \mathrm{~kb}$ double-stranded DNA genomes encoding about 30 open reading frames, and are 70-90 nm in diameter. The three major structural proteins are the hexon, penton base, and fiber $(3,4)$. The hexon of the viral capsid is key in terms of humoral immune response induction. CAV-1 targets the digestive tract, causing infectious hepatitis; CAV-2 targets respiratory tissues, triggering infectious laryngotracheitis in dogs and wild carnivores $(5,6)$. In the time since CAV-1 was first isolated from a dog in 1954, $C A V-1$ infections have been reported in the Eurasian rover otter, the fennec fox, and dogs from many countries including Korea $(7,8)$. The most common symptoms of CAV-1-infected dogs are fever, weakness, vomiting, diarrhea, cough, corneal edema (blue eye), and death (9). Anti-CAV vaccination has significantly reduced infections in dogs in Korea and other developed countries (10). CAV-1 antibodies induced by vaccination or natural infection can be detected by 
several methods such as hemagglutination (HI), virus neutralization (VN), enzyme-linked immunosorbent assay (ELISA), and the indirect immunofluorescence assay in samples of animal serum (10-12). The HI test requires erythrocytes, and its complexity limits its utility. The $\mathrm{VN}$ test has often been used to detect anti-CAV-1 antibodies in dog sera induced by vaccination or natural infection. Although the test detects anti-CAV-1 antibodies, it cannot be employed for large-scale sero-surveillance. An ELISA optimally detects anti-CAV antibodies in serum samples, and because live virus is not required and only small amounts of serum are needed, it is easier and more rapid than the VN test. Few ELISA kits specific for CAV-1 antibody in dog sera are available. Several traditional methods are used to obtain purified antigens that can be coated onto ELISA micro-plates. Viral antigens can be concentrated by ultracentrifugation or precipitation with polyethylene glycol (PEG) 8,000, ammonium sulfate, or zinc acetate followed by filtration. After concentration, purified antigen is obtained by removing impurities such as cell debris using sucrose or cesium chloride density gradients. Newer methods include column chromatography and tangential flow filtration systems $(13,14)$. In this study, we purified CAV-1 antigen in a Nuvia CPrime column filled with a hydrophobic exchange medium, and established an indirect ELISA (I-ELISA) method to detect CAV-1 antibodies in dog serum; we evaluated the new assay.

\section{MATERIALS AND METHODS}

\section{Cells, virus, and serum samples}

Madin-Darby canine kidney (MDCK) cells (CCL34; ATCC, Manassas, VA, USA) were maintained in Dulbecco's modified Eagle's medium (DMEM) containing 10\% (v/v) fetal bovine serum (FBS; Gibco BRL, Gaithersburg, MD., USA), penicillin (100 $\mathrm{IU} / \mathrm{mL})$, streptomycin $(100 \mu \mathrm{g} / \mathrm{mL})$, and the antimycotic amphotericin $\mathrm{B}(0.25 \mu \mathrm{g} / \mathrm{mL})$ at $37^{\circ} \mathrm{C}$ under $5 \%(\mathrm{v} / \mathrm{v}) \mathrm{CO}_{2}$, and used for viral antigen production and serological assay. The CAV1V strain of CAV-1, which is the CAV-1 vaccine used in Korea, was employed as a viral antigen. A total of 165 serum samples were collected from dogs residing in Chungbuk and Gyeongbuk provinces from 2016 to 2018, and the sera were used in each test. We do not know if the dogs had been inoculated with the CAV vaccine.

\section{Growth kinetics and hemagglutination assay}

The growth kinetics of the CAV1V strain were explored to determine the optimal harvest time in terms of antigen production. In brief, MDCK cells grown in $25 \mathrm{~cm}^{2}$ flasks were inoculated with CAV1V at $100 \mathrm{TCID} 50 / \mathrm{mL}$ and harvested daily for 7 days. After three consecutive freeze-thaw cycles, the viral titers were determined according to the method of Reed and Muench, and expressed as the $50 \%$ tissue culture infectious doses $\left(\mathrm{TCID}_{50} / \mathrm{mL}\right)$. The hemagglutination assay $(\mathrm{HA})$ was performed by incubating serial two-fold dilutions of the eluted fractions in $50 \mu \mathrm{L}$ amounts of phosphate-buffered saline (PBS, pH 7.2) at $4^{\circ} \mathrm{C}$ with $50 \mu \mathrm{L}$ amounts of $0.6 \%(\mathrm{w} / \mathrm{v})$ guinea pig erythrocytes and $0.1 \%(\mathrm{~W} / \mathrm{V})$ bovine serum albumin fraction $\mathrm{V}$. The $\mathrm{HA}$ titer was the reciprocal $\left(\log _{2}\right)$ of the highest dilution of CAV1V that exhibited HA.

\section{Virus neutralization test}

The VN test was performed according to a previously described method using MDCK cells (10). In brief, each serum sample was serially diluted twofold in 96-well microplates and CAV1V (100 TCID $50 / 50 \mu \mathrm{L})$ was added to each well. After incubation at $37^{\circ} \mathrm{C}$ for $1 \mathrm{~h}, 0.1 \mathrm{~mL}$ MDCK cell suspension $\left(2.0 \times 10^{5}\right.$ cells $\left./ \mathrm{mL}\right)$ was added to each well. The microplates were incubated and checked for cytopathic effect (CPE) over 5 days post inoculation (DPI). The virus-neutralizing antibody (VNA) titer of CAV-1 was the reciprocal of the highest serum dilution that completely inhibited the CPE. Each serum sample was diluted from 1:2 to 1:256. A VNA titer $\geq 1: 2$ was considered positive.

\section{Purification of CAV-1 virus}

MDCK cells grown in $750 \mathrm{~cm}^{2}$ roller bottles were inoculated with the CAV1V strain. After incubation at $37^{\circ} \mathrm{C}$ for $1 \mathrm{~h}$, the 
inoculated virus was removed and fresh DMEM without FBS was added. After checking for CPE at 4 DPI, CAV1V antigen was harvested by three consecutive freeze-thaw cycles. The viral suspension was filtered through a syringe filter ( $0.2 \mu \mathrm{m}$ pore) and loaded onto a $1 \mathrm{~mL}$ Nuvia cPrime column (Bio-Rad, Hercules, CA, USA) filled with a hydrophobic cation exchange medium featuring an aromatic hydrophobic ring and a COO-functional group. The column was equilibrated with 10 column volumes (CVs) of $25 \mathrm{mM}$ histidine (buffer $\mathrm{A}, \mathrm{pH}$ 6.0). The viral antigen was mixed with buffer at a volume ratio of 1:3. The mixture was applied to the Nuvia CPrime column connected to a peristaltic pump ( $P-1$; GE Healthcare Bioscience AB, Ussala, Sweden), followed by $10 \mathrm{CV}$ of buffer $\mathrm{A}$ for washing. The elution buffer was $75 \mathrm{mM}$ Tris, $525 \mathrm{mM} \mathrm{NaCl}, \mathrm{pH}$ 8.5. Each elution fraction was analyzed by measuring the total virus protein concentration and HA units using a NanoDrop 1000 UV/Vis spectrophotometer (Thermo Fisher Scientific, Waltham, MA, USA) and the HA test. The fraction with the highest spectrophotometric concentration was used as the source of I-ELISA antigen and subjected to electron microscope observation. CAV1V particles were visualized under a Hitachi 7100 transmission electron microscope (Tokyo, Japan).

\section{Optimization and application of I-ELISA}

The checkerboard titration test was used to determine optimal viral antigen coating concentrations and dilutions of serum. CAV1 antigen was coated on a 96-well microplate (MaxiSorp; Nunc, Roskilde, Denmark) at $4^{\circ} \mathrm{C}$ overnight using the following coating buffer: $0.05 \mathrm{M}$ carbonated -bicarbonate $(\mathrm{pH}$ 9.6). After discarding the unattached antigen, the plate was added with blocking buffer ( $5 \%$ skim milk in PBS). The purified CAV1V antigen at concentrations of 25 to $0.02 \mu \mathrm{g} / \mathrm{mL}$, and serum panel samples at dilutions of 1:20 to 1:40,960, were used to determine the appropriate concentrations at $37^{\circ} \mathrm{C}$ for $1 \mathrm{~h}$. Next, $100 \mu \mathrm{L}$ amounts of anti-dog lgG horseradish peroxidase (HRP) conjugate (KPL, Gaithersburg, MD, USA) were added to all well of the microplate, which was incubated for $1 \mathrm{~h}$ at the above temperature. After washing, $50 \mu \mathrm{L}$ amounts of 2' 2-azino-bis-(3-ethylbenzothiazoline) substrate (ABTS) solution were added to the plate, which was then incubated for 10 min at room temperature. Finally, stop solution (1.0\% W/v sodium dodecyl sulfate) were added to stop the reaction. The absorbance of the I-ELISA was measured at $405 \mathrm{~nm}$ in a spectrophotometer (Sunrise ELISA reader; Tecan, Switzerland). Under the optimized I-ELISA conditions, $100 \mu \mathrm{L}$ serum diluted 100 -fold in dilution buffer (1\% [w/v] skim milk in PBS) was added to a 96-well microplate coated with CAV1V antigen. After incubation at $37^{\circ} \mathrm{C}$ for $1 \mathrm{~h}$, the plate was washed with PBS containing $0.05 \%$ Tween 20 (PBST) and incubated with $100 \mu \mathrm{L}$ anti-dog lgG HRP conjugate diluted 4,000-fold in dilution buffer for $1 \mathrm{~h}$ at $37^{\circ} \mathrm{C}$. After washing, $50 \mu \mathrm{L}$ ABTS substrate solution and $50 \mu \mathrm{L}$ stop solution ( $1.0 \%$ [w/v] sodium dodecyl sulfate) were added to all wells of the microplate. Serum samples exhibiting absorbances greater than the cutoff of 0.4 were evaluated as positive. The specificity, sensitivity, and accuracy of the I-ELISA were determined as previously reported (15).

\section{Statistical analyses}

Linear regression analyses (least-squares method) were employed to determine the correlations between the absorbance of the I-ELISA and the VNA titer of CAV-1. The correlation coefficient ( $r$ value) was automatically calculated by Microsoft Excel 2010 (Microsoft Corp, Redmond, WA, USA).

\section{RESULTS}

\section{Virus production and purification of CAV-1 on the Nuvia cPrime column}

The optimal harvest time to obtain a high titer of CAV-1 was determined by the growth kinetics. The viruses harvested at 4 and 5 DPI afforded the highest titers of $10^{7.5} \mathrm{TCID}_{50} / \mathrm{mL}$ (Fig. 1A). At $4 \mathrm{DPI}$, approximately $80 \%$ of MDCK cells infected with the CAV1V strain showed CPE resembling bunches of grapes and were fixed in $80 \%(\mathrm{~V} / \mathrm{V})$ cold acetone. The cells were stained with a monoclonal antibody against CAV-1 and an anti-mouse IgG-FITC conjugate; specific fluorescence was evident in nuclei (Fig. 1B). Based on the CAV1V growth kinetics, viral antigen was harvested at around 4 DPI and purified. CAV1V antigen for I-ELISA was purified using the Nuvia cPrime column (Fig. 2A). The highest protein concentration ( $2.9 \mathrm{mg} / \mathrm{mL}$ ) and the highest HA titer $\left(2^{11}\right)$ were evident in the seventh eluate, as determined using the NanoDrop spectrometer and the HA 
assay (Fig. 2B). Electron microscopy revealed intact icosahedral viral particles (Fig. 2C).

A

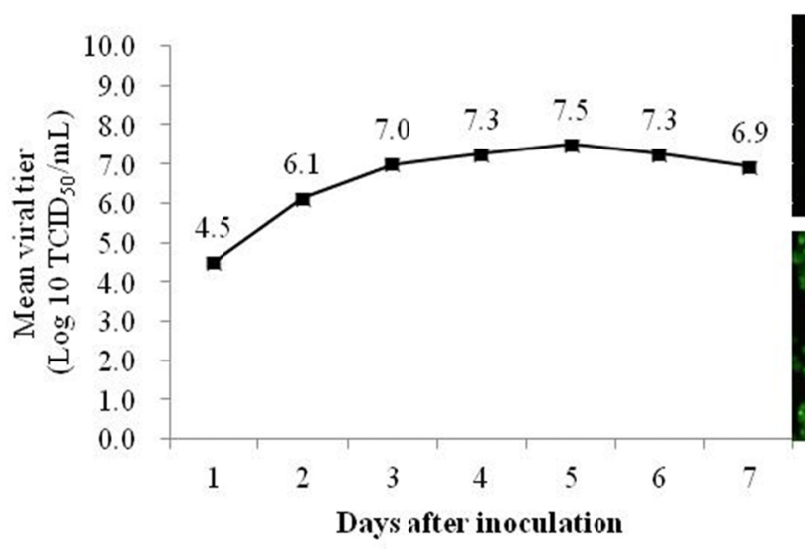

$\mathrm{B}$

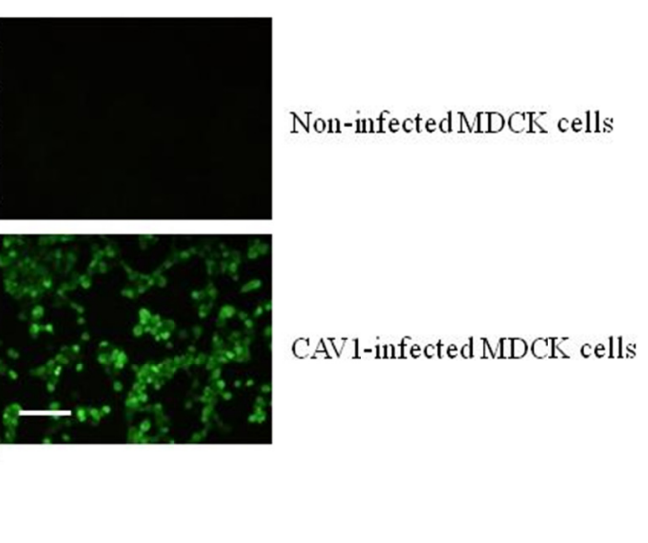

Fig. 1. Optimal harvesting time determined via analyses of the CAV1V growth kinetics (A). The titer of CAV1V propagated in MDCK cells was measured two times and expressed as mean viral titer. Infected MDCK cells (staining with monoclonal antibody against CAV-1 and the anti-mouse lgG FITC conjugate) show specific nuclear fluorescence (B), Scale bars, $100 \mu \mathrm{m}$.
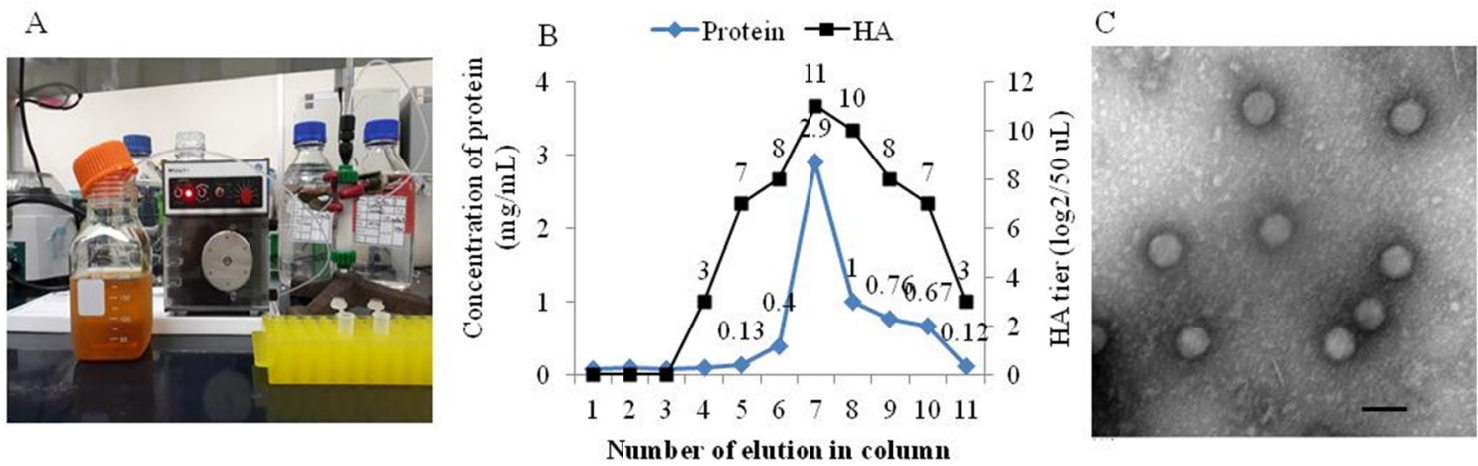

Fig. 2. CAV-1 antigen loaded onto a Nuvia cPrime column connected to a peristaltic pump (P-1) (A). The concentrations of proteins eluted from the Nuvia cPrime column and their hemagglutinating activities as measured using NanoDrop 1000 UV/Vis spectrophotometry and admixture with $0.6 \%(\mathrm{v} / \mathrm{v})$ guinea pig erythrocytes, respectively (Bi). Canine adenovirus type 1 particles were evident via electron microscopy of the seventh eluate, scale bar, $100 \mathrm{~nm}$ (C).

\section{Optimization and application of I-ELISA}

The optimal antigen concentration and serum dilution were $5 \mu \mathrm{g} / \mathrm{mL}$ and 1:100 (Fig. 3A and B). The blocking buffer was $1 \%$ (w/v) skim milk in PBS and anti-dog IgG HRP conjugate at a concentration of $10 \mathrm{ng} / \mathrm{mL}$ was used to optimize the I-ELISA. ABTS and $1.0 \%(\mathrm{w} / \mathrm{v})$ sodium dodecyl sulfate solution were used as the substrate and stop solutions, respectively. An absorbance of 0.4 was the cutoff value; an absorbance value $>0.4$ on I-ELISA was considered positive.

The specific CAV-1 lgG antibody and VNA titers in 165 dog serum samples were obtained using the I-ELISA and VN test, respectively. The absorbances obtained via I-ELISA were compared to the VNA titers determined in the VN test to evaluate diagnostic reliability. As shown in Table 1, 134 samples were VN-positive, with VNA titers ranging from 1:2 to 1:256, while 138 were positive in I-ELISA, with absorbances $>0.4$. Overall, 31 and 27 CAV-1-negative samples were recorded in the VN 
test and I-ELISA, respectively. Figure 4 shows the correlations between I-ELISA and VN data, as indicated by regression lines and correlation coefficients $(r)$. The r-value for the $V N$ test was 0.88 . Based on the CAV-1-positive/negative data from the $V N$ test, the sensitivity, specificity, and accuracy of I-ELISA were $97.0 \%, 74.2 \%$, and $92.7 \%$, respectively, compared to the results of the $\mathrm{VN}$ test (Table 1).

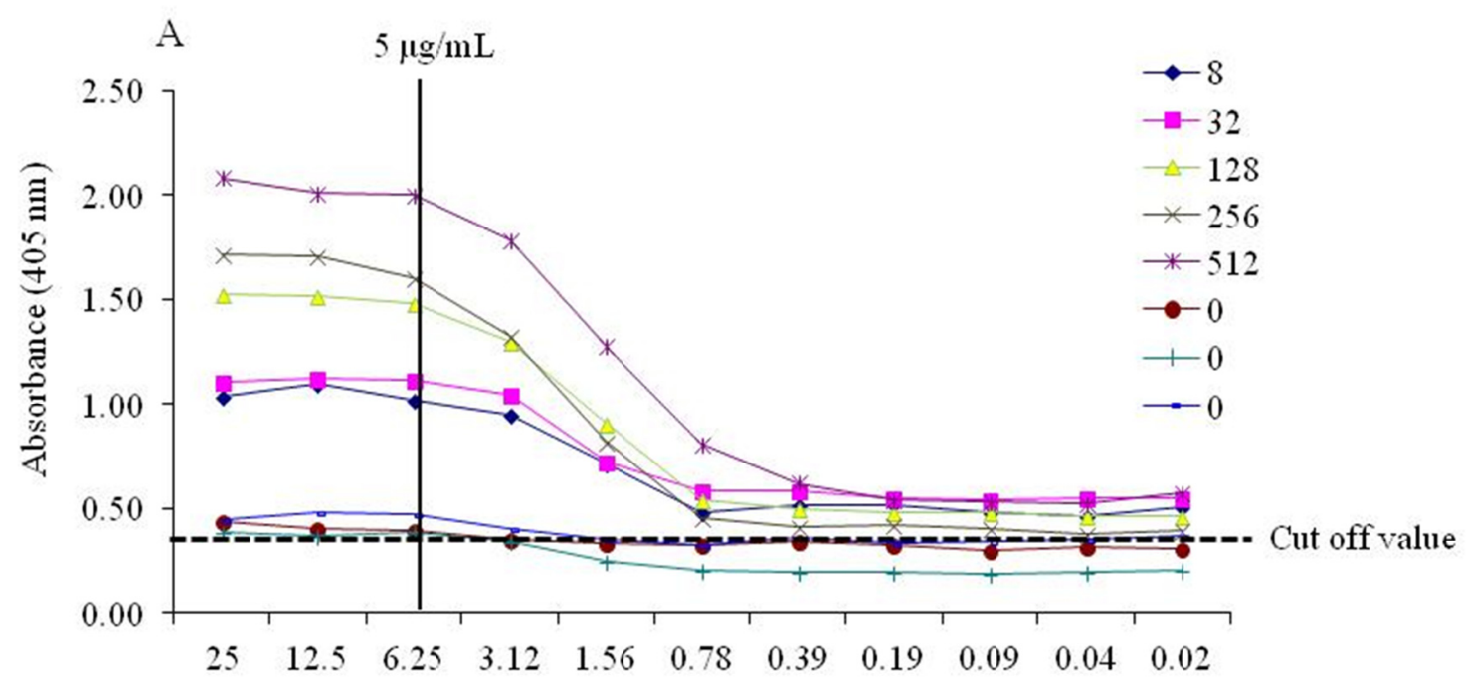

Concentration of antigen $(\mu \mathrm{g} / \mathrm{mL})$

B $1: 100$ (serum dilution)

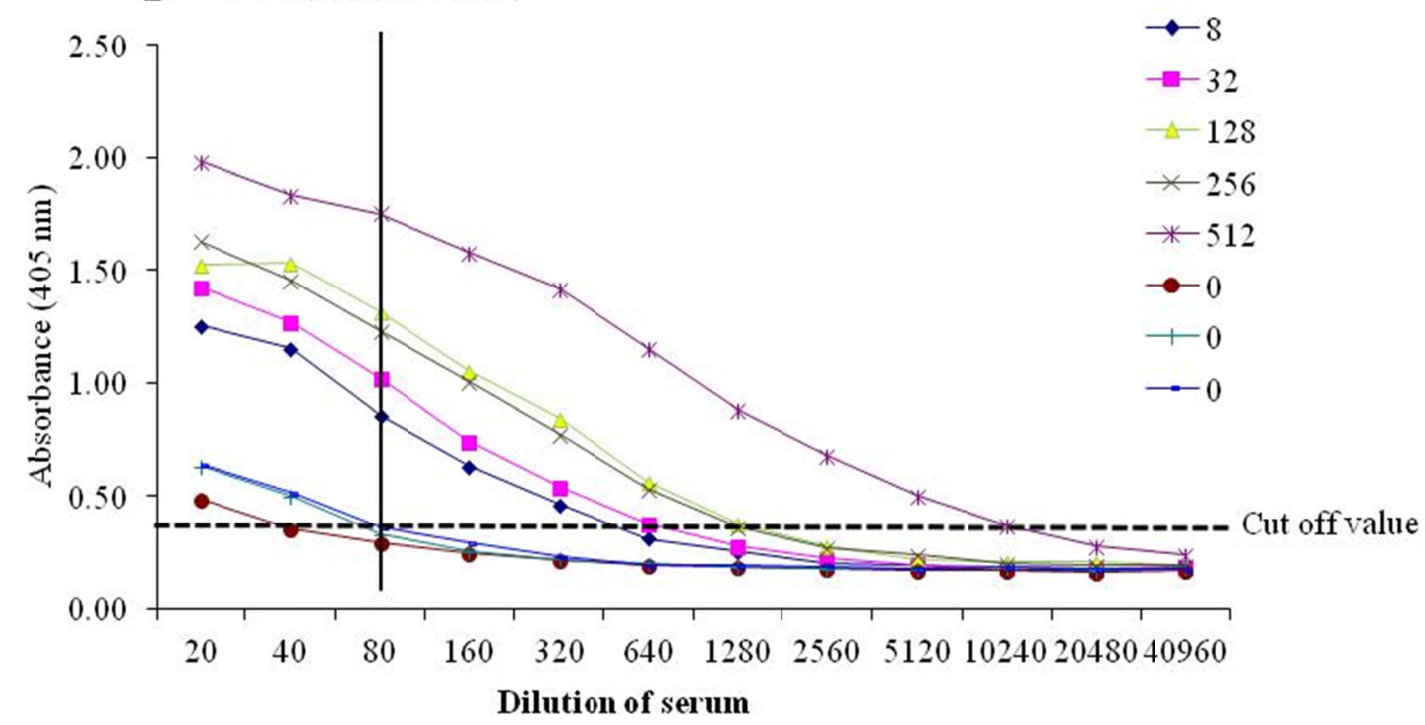

Fig. 3. Determination of the concentration of the purified CAV-1 antigen $(A)$ and serum dilution $(B)$ by indirect enzyme-linked immunosorbent assay (I-ELISA). The concentrations of antigen and dilutions of serum were analyzed according to cut-off values (>0.4). The numbers in the legend are the virus-neutralizing antibody (VNA) titers (0-512) of CAV-1 in dog serum. 


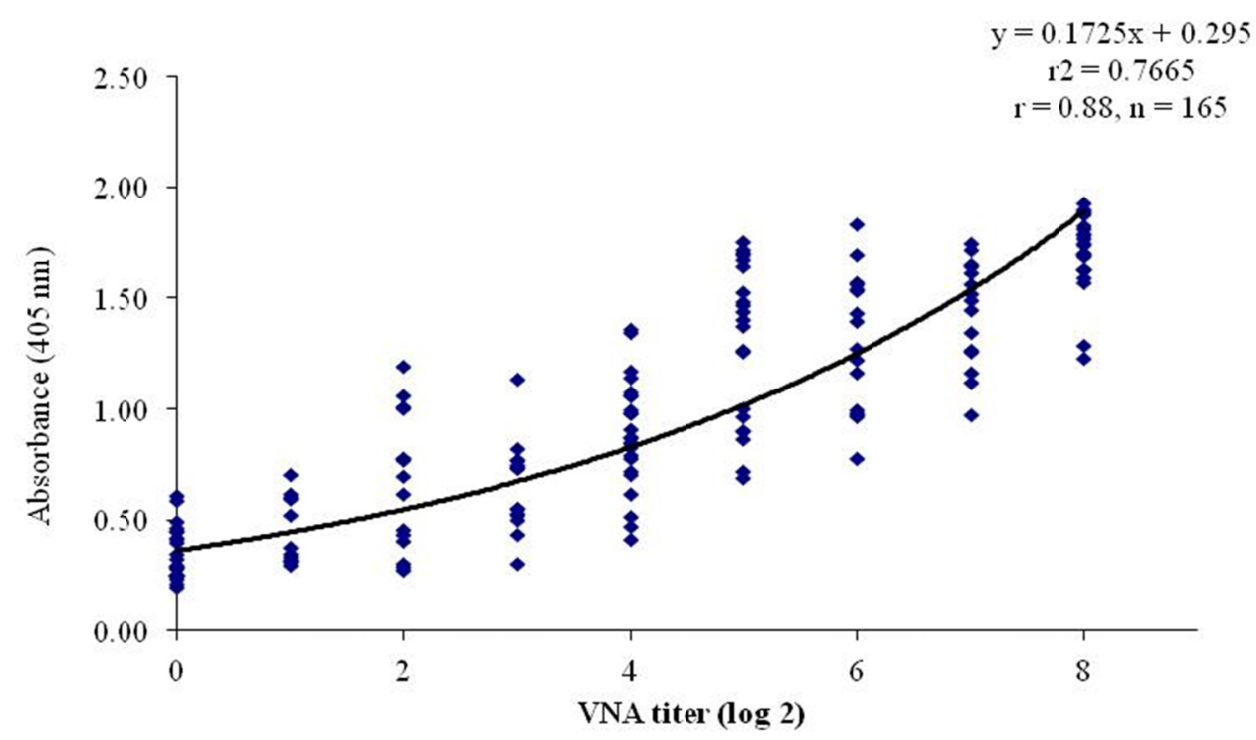

Fig. 4. Correlation between the VNA titer and absorbance of I-ELISA for detecting CAV-1 antibodies in 165 dog serum samples. The correlation is indicated by the linear regression line and $r$-value (0.88).

Table 1. The sensitivity, specificity, and accuracy of I-ELISA for the detection of CAV-1 antibodies compared to the VN test

\begin{tabular}{|c|c|c|c|c|}
\hline & & \multicolumn{3}{|c|}{ VN test } \\
\hline & & Positive & Negative & Sum \\
\hline & Positive & 130 & 8 & 138 \\
\hline \multirow[t]{5}{*}{ I-ELISA } & Negative & 4 & 23 & 27 \\
\hline & Sum & 134 & 31 & 165 \\
\hline & Sensitivity ${ }^{*}$ & \multicolumn{2}{|c|}{$97.0 \%$} & \\
\hline & Specificity $^{\dagger}$ & \multicolumn{2}{|c|}{$74.2 \%$} & \\
\hline & Accuracy ${ }^{\#}$ & \multicolumn{2}{|c|}{$92.7 \%$} & \\
\hline
\end{tabular}

*Sensitivity $(\%)=$ (number of positive results in both tests/total number of positive results in the reference test) $\times 100$, 'Specificity $(\%)=$ (number of negative results in both tests/total number of negative results in the reference test) $\times 100$, ${ }^{\#}$ Accuracy $(\%)=$ (actual number of both positive and negative results/total number of samples) $\times 100$.

\section{DISCUSSION}

As CAV-1 causes canine infectious hepatitis, routine vaccination has been implemented in Korean dogs. However, few studies have investigated CAV-1 sero-surveillance or serological methods used to measure anti-CAV-1 antibodies in Korean animals after vaccination or natural exposure to CAV-1. Although the VN test yields accurate VNA titers, ELISA offers several advantages, being relatively simple and rapid. In addition, ELISA is suitable for large numbers of serum samples and needs only small amounts of serum. For these reasons, we aimed to develop an I-ELISA method for sero-surveillance of CAV-1 in dogs.

The classic method used to obtain highly purified viral antigens features two steps. The first step is to concentrate the whole-virus antigen using PEG 8,000, ammonium sulfate $\left(\left(\mathrm{NH}_{4}\right)_{2} \mathrm{SO}_{4}\right)$, or zinc acetate, followed by filtration $(16,17)$. The second step is antigen purification via sucrose or $\mathrm{CsCl}$ gradient centrifugation (18). As the above methods feature 
ultracentrifugation, they may be not suitable for purifying large volumes of medium containing virus of low titer. When developing an I-ELISA with high sensitivity and specificity, it is critical to use highly purified viral antigen (19). Most CAVs are in the cell nuclei. The technique used depends on the number and nature of the cells being extracted. We used a new chromatographic method to purify CAV-1 antigen for I-ELISA. The most recommended chromatographic method for adenovirus purification is anion-exchange chromatography, which takes advantage of the strong negative charge and high binding capacity of the virus (20-23). We purified whole CAV-1 using a Nuvia cPrime column filled with a polymer. We obtained high viral and HA titers; viral particles were observed via electron microscopy in the seventh eluate. A disadvantage is that bovine serum albumin in growth medium also attaches to the column (23). Therefore, we propagated CAV1V in medium without FBS. Our method may be extended to other adenoviruses isolated from various animals.

We analyzed the results of our new test in terms of sensitivity, specificity, accuracy, and correlations; we used 165 dog serum samples. The overall accuracy (92.7\%) of I-ELISA was slightly lower than that (98\%) obtained by Noon et al. (12). In our study, the sensitivity (97.0\%) of I-ELISA used to detect CAV-1 antibody was higher than the specificity (74.2\%). Factors that affect I-ELISA specificity are the assay plate; the blocking, serum dilution, and washing buffers; and the purity of viral antigen. We found four and eight differences, respectively, between the 134 positive and 31 negative samples. Of $31 \mathrm{VN}$-negative samples, 8 were missed by I-ELISA ( $25.8 \%$ false-negative rate), indicating that more highly purified CAV-1 antigen may have a high potential for lowering false-negative rate (19). For the industrialization of the developed I-ELISA, it is necessary to consider the method of using both sucrose density gradients and column chromatography for the purification of CAV-1. Our results also showed that the absorbance result of the I-ELISA was significantly correlated with that of the VNA titer $(r=0.88)$, suggesting a strong relationship between I-ELISA and VN test data. Therefore, the newly developed I-ELISA is as reliable as the $\mathrm{VN}$ test.

In conclusion, we showed that the results of I-ELISA using CAV-1 antigen purified on a Nuvia CPrime column were significantly correlated with those of the VN test in terms of detecting anti-CAV-1 antibodies in dog sera. Thus, our new I-ELISA assay can serve as a simple and efficient tool for CAV-1 sero-surveillance in dogs.

\section{Acknowledgments}

This work was supported financially by a grant (B-1543083-2018-19-04) from the Animal, and Plant Quarantine Agency, Ministry of Agriculture, Food and Rural Affairs, Republic of Korea.

\section{REFERENCES}

1) Hu RL, Huang G, Qiu W, Zhong ZH, Xia XZ, Yin Z. Detection and differentiation of CAV-1 and CAV-2 by polymerase chain reaction. Vet Res Commun 2001:25:77-84.

2) Timurkan MO, Aydin H, Alkan F. Detection and molecular characterization of canine adenovirus type 2 (CAV-2) in dogs with respiratory tract symptoms in shelters in Turkey. Veterinarski arhiv 2018;88:467-79.

3) Liu YC, Abouhaidar MG, Sira S, Campbell JB. Characterization of the genome of a vaccine strain of canine adenovirus type 1. Virus Genes 1988;2:69-81.

4) Russell WC. Adenoviruses: update on structure and function. J Gen Viro/2009;90:1-20.

5) Walker D, Abbondati E, Cox AL, Mitchell GB, Pizzi R, Sharp CP, et al. Infectious canine hepatitis in red foxes (Vulpes vulpes) in wildlife rescue centres in the UK. Vet Rec 2016:178:421. 
6) Buonavoglia C, Martella V. Canine respiratory viruses. Vet Res 2007;38:355-73.

7) Choi JW, Lee HK, Kim SH, Kim YH, Lee KK, Lee MH, et al. Canine adenovirus type 1 in a fennec fox (Vulpes zerda). J Zoo Wildl Med 2014;45:947-50.

8) Cabasso VJ. Infectious canine hepatitis virus. Ann N Y Acad Sci 1962;101:498-514

9) Wong M, Woolford L, Hasan NH, Hemmatzadeh F. A Novel Recombinant Canine Adenovirus Type 1 Detected from Acute Lethal Cases of Infectious Canine Hepatitis. Viral Immuno/2017;30:258-63.

10) Yang DK, Kim HH, Yoon SS, Ji M, Cho IS. Incidence and Sero-survey of Canine Adenovirus Type 2 in Various Animal Species. J Bacterio/ Viro/2018;48:102-8.

11) Marusyk RG, Yamamoto T. Characterization of a canine adenovirus hemagglutinin. Can J Microbio/1971;17:151-5.

12) Noon KF, Rogul M, Binn LN, Keefe TJ, Marchwicki RH, Thomas R, et al. An enzyme-linked immunosorbent assay for the detection of canine antibodies to canine adenoviruses. Lab Anim Sci 1979;29:603-9.

13) Segura MM, Puig M, Monfar M, Chillón M. Chromatography purification of canine adenoviral vectors. Hum Gene Ther Methods 2012:23:182-97.

14) Coronel J, Behrendt I, Bürgin T, Anderlei T, Sandig V, Reichl U, et al. Influenza A virus production in a single-use orbital shaken bioreactor with ATF or TFF perfusion systems. Vaccine 2019;37:7011-8.

15) Muhamuda K, Madhusudana SN, Ravi V. Development and evaluation of a competitive ELISA for estimation of rabies neutralizing antibodies after post-exposure rabies vaccination in humans. Int J Infect Dis 2007;11:441-5.

16) Gschwender HH, Brummund M, Lehmann-Grube F. Lymphocytic Choriomeningitis virus. I. Concentration and purification of the infectious virus. J Viro/ 1975;15:1317-22

17) Schagen FH, Rademaker HJ, Rabelink MJ, van Ormondt H, Fallaux FJ, van der Eb AJ, et al. Ammonium sulphate precipitation of recombinant adenovirus from culture medium: an easy method to increase the total virus yield. Gene Ther 2000;7:1570-4.

18) Kanegae $Y$, Makimura M, Saito I. A simple and efficient method for purification of infectious recombinant adenovirus. Jpn J Med Sci Bio/ 1994;47:157-66.

19) Yang DK, Kim HH, Lee SH, Ji M, Cho IS. Indirect ELISA for the Detection of Rabies Virus Antibodies in Dog Sera. J Bacterio/ Viro/2017;47:148-55.

20) Burova E, loffe E. Chromatographic purification of recombinant adenoviral and adeno-associated viral vectors: methods and implications. Gene Ther 2005;12 Suppl 1:S5-17.

21) Konz JO, Livingood RC, Bett AJ, Goerke AR, Laska ME, Sagar SL. Serotype specificity of adenovirus purification using anion-exchange chromatography. Hum Gene Ther 2005;16:1346-53.

22) Zhu M, Carta G. Protein adsorption equilibrium and kinetics in multimodal cation exchange resins. Adsorption 2016:22:165-79.

23) He Y, Gao D, Zhang M. Expression of the nucleoprotein gene of rabies virus for use as a diagnostic reagent. J Viro/ Methods 2006:138:147-51. 